\title{
ANXIETY AND EATING DISORDERS DURING THE QUARANTINE OF COVID-19: AN OBSERVATIONAL STUDY
}

Dr. Idiberto Jose Zotarelli Filho, MSc, Ph.D ${ }^{1}$

${ }^{1}$ Affiliation not available

September 29, 2020

\begin{abstract}
Beatriz Colovati Saccardo ${ }^{1}$, Camila Saggioro Paulucci ${ }^{1}$, Pedro Saggioro Paulucci ${ }^{1}$, Heloisa Dias Sanson ${ }^{1}$, Otávio Carbone Ruy ${ }^{1}$, Durval Ribas Filho ${ }^{1,2}$, Ana Valéria Garcia Ramirez ${ }^{2,5}$, Idiberto José Zotarelli Filho ${ }^{2,3,4}$
\end{abstract}

1. FAMECA, Faculty of Medicine of Catanduva - Padre Albino University Center, Catanduva/SP, Brazil.

2. Associação Brasileira de Nutrologia (ABRAN)/Brazilian Association of Nutrology, Catanduva/SP, Brazil.

3. $\quad$ FACERES - Faculdade de Medicina de São José do Rio Preto/SP, Brazil.

4. Zotarelli-Filho Scientific Work, São José do Rio Preto/SP, Brazil.

5. Ana Valeria Ramirez Clínica- Clinic of Nutrition and Health Science, São José do Rio Preto SP, Brazil.

Corresponding Author: Dr. Idiberto José Zotarelli Filho, MsC, Ph.D. FACERES- Medical School, São José do Rio Preto SP, Brazil; email: dr.idibertozotarelli@faceres.com.br

\begin{abstract}
During quarantine, imposed in a pandemic situation by COVID-19, fears, and uncertainties, in addition to social isolation, are characterized as risk factors for the mental health of the general population and the effects can be felt through the manifestation of conditions anxious, depressive or even binge eating. Binge eating can be caused by anxiety, especially during quarantine, and the act of eating is often linked to a way of relieving negative feelings. The research in question was carried out using an online questionnaire, based on the Hamilton Anxiety Scale and on the symptoms of binge eating defined by the Brazilian Society of Neuropsychology. The questionnaire covered 944 people, who answered questions about the theme "anxiety and binge eating during quarantine", $76.9 \%$ were female and $23 \%$ male. Of these people, $80 \%$ said they ate to escape from worries or relieve stress in this period of the pandemic, when questioning how much the frequency of meals per day and quantity changed, there were no significant changes, however, approximately $50 \%$ of people at least doubled their consumption of industrialized foods, sweets, and fast foods. Most people (80\%) are feeling a greater fear than normal, in addition to feeling that this isolation is affecting mental health and routine and $78.6 \%$ have already experienced shortness of breath, palpitations, or restlessness during this period. This group of people stated that this moment has negatively affected their daily activities, on a scale of $1-10,76.5 \%$ placed it at 5-10. It was asked about the presence of mood swings, negative thoughts, and discouragement, $73.8 \%$ of people answered yes, in addition, on a scale of 1-10, $50 \%$ were between $5-10$ when the question was the search food as a way to feel better. Finally, $82.1 \%$ of people said they were more anxious in the quarantine period. Regarding the results, there was a pattern indicating a correlation between
\end{abstract}


anxiety and higher levels of stress and behavior in which food has a compensatory role towards this psychic imbalance possibly caused by quarantine. The first question in the questionnaire is broad and serves as an overview of how much food is a frequent thought for respondents. In it, $64 \%$ "said sometimes" and $15 \%$ "always" think about food during the day. As for the frequency with which they eat, the results indicated that only $37 \%$ of the interviewees showed a significant increase. However, when it comes to food quality, more than $20 \%$ scored between 8 and 10 on a scale of 0 to 10, when it comes to increased consumption of processed foods. Showing worsening in the nutritional quality of the interviewees. It is concluded that the majority of people who answered the questionnaire reported signs that indicate the occurrence of anxiety, based on the Hamilton scale, such as fear and worry. Depending on these data, there was an increase in the consumption of processed foods, sweets, and fast foods, which are more accessible and palatable, leading to a feeling of pleasure at specific times.

Keywords: Quarantine. Anxiety. Eating disorders.

\section{INTRODUCTION}

Social isolation can affect people's routines and mental health. The effects can be felt through the manifestation of anxiety, depression, or even binge eating. Studies on impacts on mental health due to the pandemic of the new coronavirus are still scarce, as it is a recent phenomenon, but point to important negative repercussions [1].

Gordilho (2020), explains that binge eating may have its cause in an anxiety situation, especially during a quarantine. During this period, some degree of anxiety may develop in the face of uncertainties, fear, and distance from family and friends [1].

A similar situation occurred in 2003, during the Severe Acute Respiratory Syndrome Coronavirus -SARS epidemic, another type of coronavirus, when the psychological impacts of the disease were greater than the medical impacts, in terms of the number of people affected and how long they were affected [3].

The rapid spread of the new coronavirus throughout the world, the uncertainties about how to control the disease, the seriousness of it, as well as the unpredictability about the duration of the pandemic and its consequences, are characterized as risk factors for the mental health of the population. general population [4]. This scenario also seems to be aggravated by the dissemination of video clips and alarming messages about COVID-19 through smartphones and computers, often causing panic [5]. Likewise, false news has been shared at times contrary to the guidelines of health authorities and minimizing the effects of the disease $[6,7]$.

In a literature review on quarantine, Brooks et al. (2020) [8] identified that the negative effects of this measure include symptoms of post-traumatic stress, confusion, and anger. Concerns about the scarcity of supplies and financial losses also cause damage to psychological well-being [9]. Symptoms of depression, anxiety, and stress in the face of the pandemic have been identified in the general population [10].

During quarantine, the reduced possibility of exercising increases the fear of weight gain, and the storage of non-perishable foods leads to massive exposure to crackers, snacks, frozen dishes, soft drinks, and the like. Still, the reduction of the relationship with other people or, in the opposite direction, greater tension in the face of occasional social encounters, are factors that cause some anxiety, being potential triggers for episodes of binge eating [11].

Compulsion is usually the result of a combination of factors, including genetic, emotional characteristics related to life experiences. Binge eating or Periodic Eating Compulsion Disorder (BED) is an eating disorder characterized by recurrent episodes of binge eating, where large amounts of food are eaten quickly until you feel discomfort, even when not hungry, accompanied by a feeling of a total loss of control. The person suffering from binge eating experiences shame, anguish, or guilt after the binge episode [12]. Binge eating 
occurs, on average, at least once a week for a minimum period of 3 months. Binge eating is not related to the repetition of inappropriate compensatory behaviors (eg, vomiting) as in the case of bulimia.

One of the most common reasons for binge eating is an attempt to manage unpleasant emotions, such as stress, depression, loneliness, fear, and anxiety. But the function of food is to nourish the organism and when used to fill an emotional gap, it is effective only temporarily, as emptiness always comes back together with the feeling of guilt since food works as an immediate emotional reward mechanism [13].

Thus, it is possible to see the relationship between anxiety and Periodic Eating Compulsion Disorder, intensified during quarantine, in a pandemic scenario, which requires social isolation. Therefore, the present observational and cross-sectional study analyzed the relationship between anxiety and binge eating during the quarantine of COVID-19.

\section{METHODS}

The research in question is an observational, transversal, descriptive, and quantitative study. Data collection was carried out in cities in the interior of São Paulo using an online questionnaire, based on the Hamilton Anxiety Scale and the main symptoms of binge eating defined by the Brazilian Society of Neuropsychology, composed of 16 direct questions for the people interviewed. about the theme of the relationship between anxiety and binge eating during quarantine [13].

The questionnaire was developed specifically for this study by the authors of this study, during the month of May 2020 and was available for answers during the months of May, June, and July 2020. In addition, the informed consent form was duly applied. Through it, an extensive and direct observation was made on the subject, obtaining data from 944 people of different age groups, sex, occupations, and cities in the interior of São Paulo.

\section{RESULTS}

The questionnaire covered 944 people, who answered questions about the topic "anxiety and binge eating during quarantine". All of them accepted the free and informed consent form. As for sex, $76.9 \%$ were female and $23 \%$ male.

1. Do you think about food all the time (for example, do you have a meal thinking about the next one?

- 64.5\% (609 people) posted sometimes, 20.6\% (194 people) never posted and 14.6\% (141 people) always posted.

2. Do you eat to escape from worries, relieve stress, or to comfort yourself?

- $73.2 \%$ (691 people) did it at specific times, 19.2\% (181 people) never did it and $7.6 \%$ (72 people) did it at all meals.

3. Do you eat until you feel full (do you eat even after satiety)?

- 41.1\% (388 people) posted more than twice a week, 36.5\% (345 people) posted once a week and $22.4 \%$ (211 people) never posted.

4. Do you eat in secret / are you ashamed of how much you eat?

- $66.7 \%$ (630 people) said no, 23.2\% (219 people) said the times and 10.1\% (95 people) said yes.

5 . Do you feel guilty at times when you overeat?

- $45 \%$ (425 people) said yes, $30.3 \%$ (286 people) said the times and $24.7 \%$ (233 people) said no.

6. How much has the frequency of eating per day increased at this time?

- It was analyzed on a scale of $1-10.20 .4 \%$ (193 people) put $1 ; 13.8 \%$ (130 people) put $2 ; 15.5 \%$ (146 people) put $3 ; 12 \%$ (113 people) put $4 ; 15.8 \%$ (149 people) put $5 ; 6.6 \%$ (62 people) put $6 ; 6.4 \%$ (60 people) put 7 ; $6.5 \%$ (61 people) put $8 ; 1.3 \%$ (12 people) put 9 and $1.9 \%$ (18 people) put 10 (Figure 1 ). 
Figure 1. How often you eat each day.

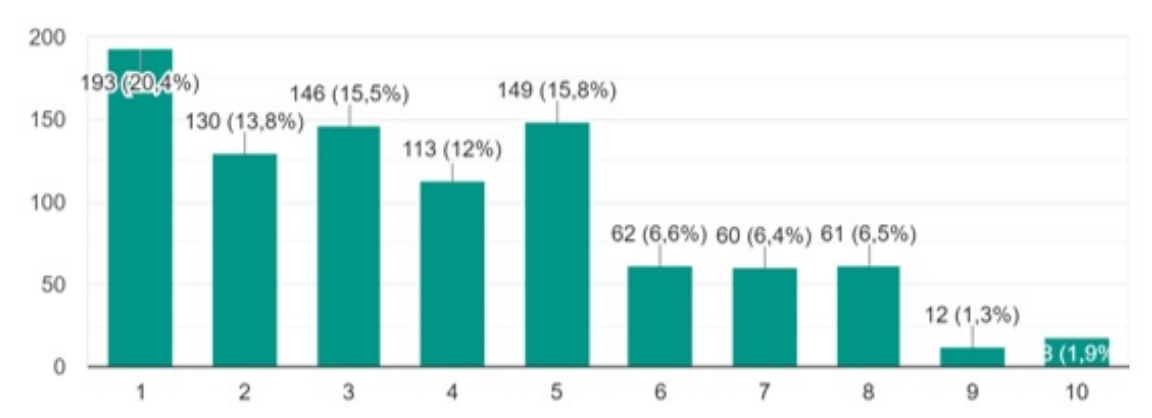

1. How much has your food amount increased per meal?

It was analyzed on a scale of $1-10.28 \%$ (264 people) put $1 ; 19 \%$ (179 people) put $2 ; 16.6 \%$ (157 people) put $3 ; 8.8 \%$ (83 people) put $4 ; 13.3 \%$ (126 people) put $5 ; 3.6 \%$ (34 people) put $6 ; 3.1 \%$ (29 people) put $7 ; 4.2 \%$ (40 people) put 8; 0.6\% (6 people) put 9 and $2.8 \%$ (26 people) put 10 (Figure 2).

Figure 2. Increase in the amount of food per meal.

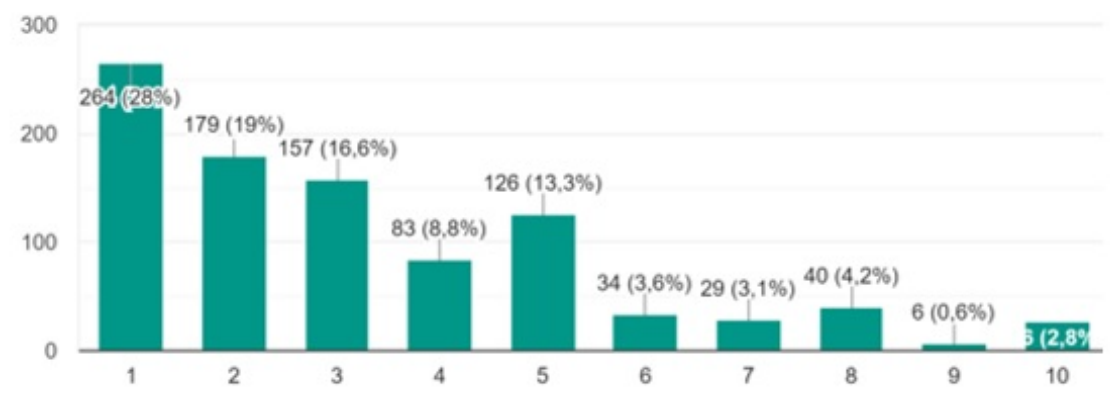

1. How much has the consumption of processed foods, sweets, fast foods, among others, increased?

It was analyzed on a scale of $1-10.23 .2 \%$ (218 people) put $1 ; 11.4 \%$ (108 people) put $2 ; 9.4 \%$ (89 people) put $3 ; 8.8 \%$ (83 people) put $4 ; 12.8 \%$ (121 people) put $5 ; 5.2 \%$ (49 people) put $6 ; 7.4 \%$ (70 people) put 7 ; $9.3 \%$ (88 people) put $8 ; 4.2 \%$ (40 people) put 9 and $8.3 \%$ (78 people) put 10 (Figure 3 ).

Figure 3. Increased consumption of processed foods, sweets, fast foods. 


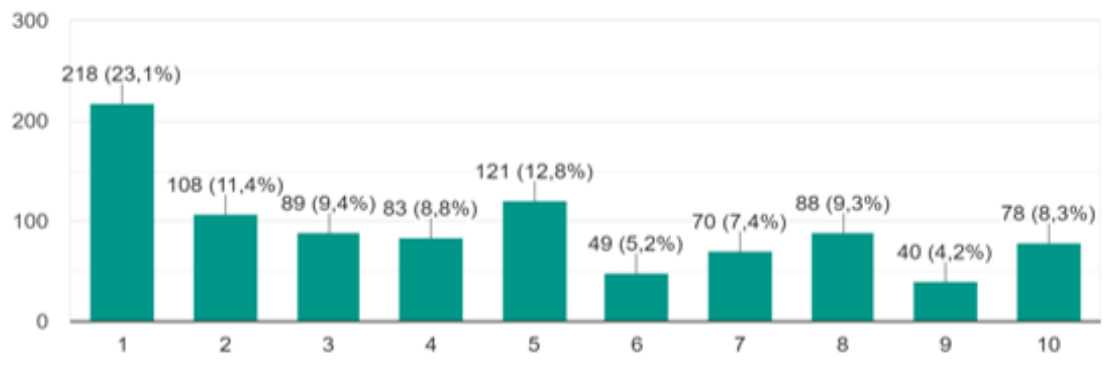

1. Do you feel that at this moment you are feeling a greater fear and concern than usual? $80.2 \%$ (757 people) said yes and $19.8 \%$ (187 people) said no.

2. If you answered yes to the previous question, do you feel that it has hindered your mental health and routine?

- It was analyzed by a scale of $1-10.8 .3 \%$ (67 people) put $1 ; 5.5 \%$ (44 people) put $2 ; 5.5 \%$ (44 people) put $3 ; 5 \%$ (40 people) put $4 ; 14.1 \%$ (114 people) put $5 ; 8.2 \%$ ( 66 people) put $6 ; 10.3 \%$ (83 people) put $7 ; 17.4 \%$ (140 people) put 8; 6.3\% (51 people) put 9 and $19.5 \%$ (157 people) put 10 (Figure 4 ).

Figure 4. Has the increased consumption of processed foods, sweets, fast foods hindered your mental health and routine?

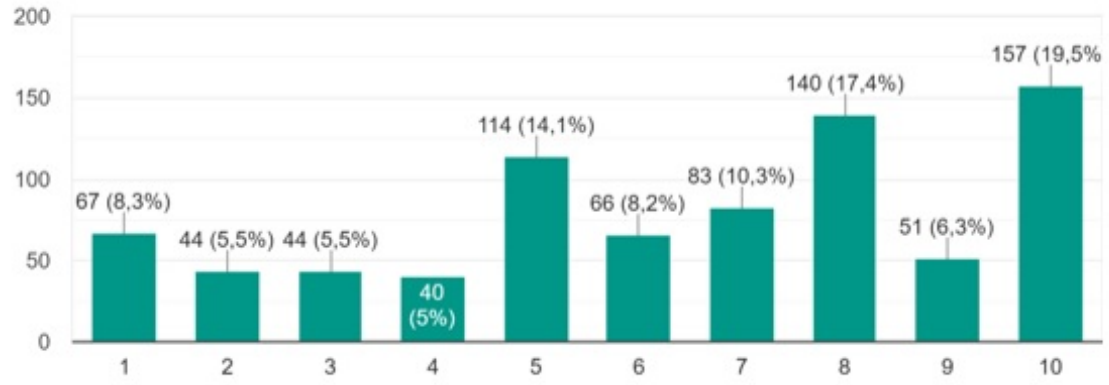

1. During quarantine, did you have feelings of shortness of breath, palpitations, or restlessness?

- 52\% (491 people) answered sometimes, 31.4\% (296 people) answered never and 16.6\% (157 people) answered always.

2. How much has it affected you negatively to stop doing things that you were used to and now can't? (see the people you like, exercise, etc.)

- It was analyzed by a scale of $1-10.3 .7 \%$ (35 people) put $1 ; 2 \%$ (19 people) put $2 ; 4 \%$ (38 people) put 3 ; $4.7 \%$ (44 people) put $4 ; 9.1 \%$ (86 people) put $5 ; 7.5 \%$ (71 people) put $6 ; 14.1 \%$ (133 people) put $7 ; 19.1 \%$ (180 people) put $8 ; 10.9 \%$ (103 people) put 9 and $24.9 \%$ (235 people) put 10 (Figure 5 ).

Figure 5. The negative impact of not doing routine things. 


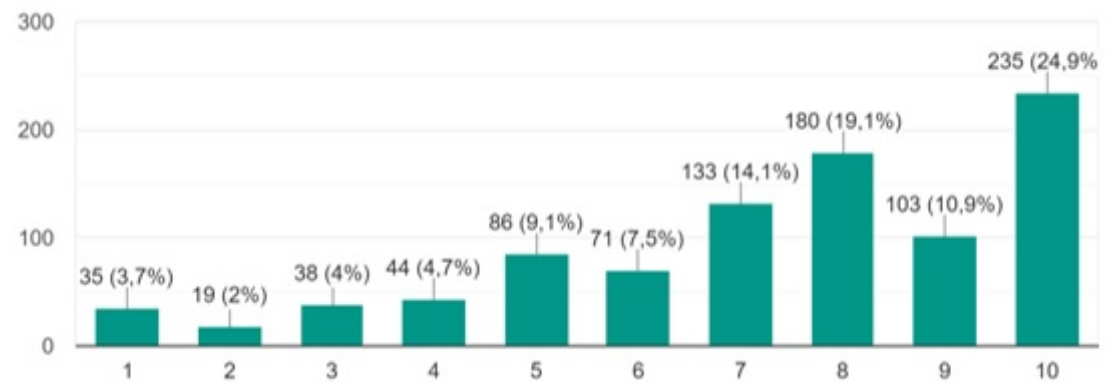

1. Have you been experiencing a major change in mood, negative thoughts, and discouragement at this time?

- 73.8\% (697 people) answered yes and 26.2\% (247 people) answered no.

2. Have you had more difficulty sleeping during this period?

- 58.3\% (550 people) answered yes and 41.7\% (394 people) answered no.

3. During periods like this, do you look for food in a way to feel better?

- It was analyzed by a scale of $1-10.21 .5 \%$ (203 people) put $1 ; 9.5 \%$ (90 people) put $2 ; 11.4 \%$ (108 people) put $3 ; 7.7 \%$ (73 people) put $4 ; 12.7 \%$ (120 people) put $5 ; 8.4 \%$ (79 people) put $6 ; 6.7 \%$ (63 people) put 7 ; 7.7\% (73 people) put 8; 3.1\% (29 people) put 9 and 11.2\% (106 people) put 10 (Figure 6).

Figure 6. Pleasure in the food?

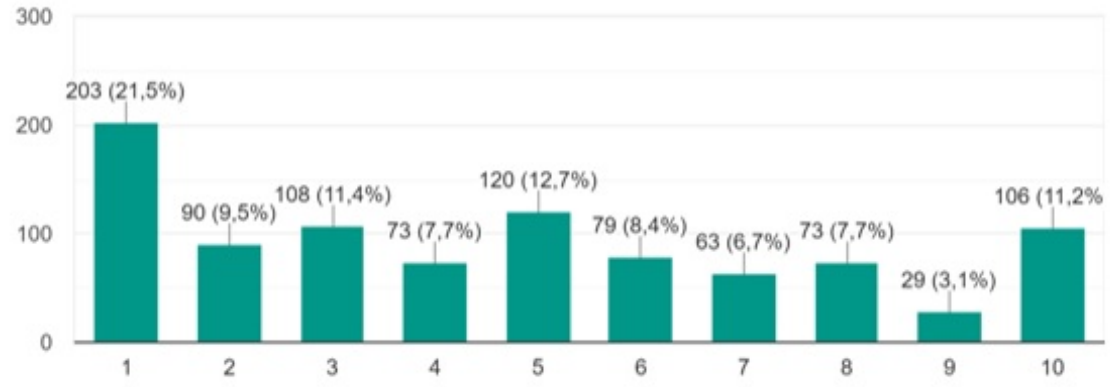

1. Do you consider yourself more anxious in this quarantine period?

82.1\% (775 people) answered yes and 17.9\% (169 people) answered no.

\section{DISCUSSION}

Regarding the results, we could see a pattern indicative of a correlation between anxiety and higher levels of stress and behavior in which food has a compensatory role towards this psychic imbalance possibly caused by quarantine. Here are the results:

The first question in the questionnaire is broad and serves as an overview of how much food is a frequent thought for respondents. In it, $64 \%$ "stated sometimes" and $15 \%$ "always" think about food during the day. We can thus associate it with two other questions that show us that $73 \%$ of respondents use food to relieve stress at specific times and $7.6 \%$ always; and that $41 \%$ of respondents eat beyond satiety more than twice 
a week and $36 \%$ once a week, which are indications of compulsive eating behavior, possibly triggered by increased anxiety in the quarantine period.

About how they feel after eating, $75 \%$ always or sometimes feel guilty, but $67 \%$ do not eat in secret nor are they ashamed of it, only $10 \%$ do so. As for the frequency with which they eat, the results indicated that only $37 \%$ of the interviewees showed a significant increase (a score of 5 to 10 on a scale of 0 to 10).

However, when it comes to food quality, more than $20 \%$ scored between 8 and 10 on a scale of 0 to 10 , when it comes to increasing consumption of processed foods (sweets, fast foods, and the like). Showing worsening in the nutritional quality of the interviewees. Henceforth, we proceeded to questions of a psychological nature based on the Hamilton anxiety scale.

A total of $80.2 \%$ of respondents reported an increase in fear/concern since the beginning of the quarantine, among them, $75 \%$ scored grades between 5 and 10 on a scale of 0 to 10 , with almost $20 \%$ having a maximum score for how much social isolation has hampered your mental health. In addition, only $31.4 \%$ had no feeling of shortness of breath, palpitation, or restlessness during social isolation. Another result that is in line with the previous one is that $85 \%$ of the interviewees scored 5 or more on a scale of 0 to 10 in which the lack of coexistence with their family, friends, and loved ones has negatively affected their psychological state, being that $25 \%$ of respondents scored 10 in this regard. In addition, $73.8 \%$ reported mood swings, negative thoughts, and discouragement and $58 \%$ reported difficulty sleeping.

Finally, there was a scattered result on the question of eating to feel better. $21 \%$ had a minimum score for this aspect (grade 1), 11\% had a maximum score (grade 10), and 50\% scored from 5 to 10, which may reveal that people with compulsive eating behavior are not fully aware of this behavior, since $80.2 \%$ consider themselves more anxious due to the pandemic and the feeding patterns of the previous questions reveal a worsening in the quality of the respondents' food and an increase in the amount of food per day; and anxiety patterns were confirmed by questions based on the Hamilton anxiety scale.

In this scenario of the results of the present study, one should not only help to care for those who suffer from contracting COVID-19, but one must also address the psychological, financial, and social impact - on those who do not. The peculiarities of COVID-19 and the reaction of the public and governments to it are particularly relevant for people living with an eating disorder and those who care for them.

Traumatic events affect people's mental health. The fear of contagion and the death of family members created enormous uncertainty. Isolation brings anxiety, sadness, anger, and loneliness. Social detachment and "quarantine" are against human nature. The negative emotional effects of "quarantine" are likely to be accentuated for many individuals with anorexia nervosa who are already emotionally and physically isolated [14].

In this sense, people with an eating disorder have a complex problematic relationship with food, which will be intensified at this time of food insecurity and panic buying [14]. Undoubtedly, there will be an abundance of research in the coming months and years documenting the impact that COVID-19 will have on the eating disorders community, both from the perspective of the clinician and the patient. In addition, there are similarities between previous outbreaks and the COVID-19 pandemic, as these outbreaks have resulted in an increasing sense of foreboding and fear, as well as heightened feelings of anxiety and panic and symptoms associated with post-traumatic stress disorder. [15].

In addition, many people with bulimia nervosa and binge eating disorder now stay at home 24 hours a day, seven days a week. There is no escape from distancing yourself from food at home and the opportunities to go out and buy food are limited. Overeating with family food when refueling is problematic can lead to more family conflicts, increased emotional arousal, depression, and anxiety, as well as the likelihood of increased self-harm or even suicide [15].

\section{CONCLUSION}

It is concluded that the majority of people who answered the questionnaire reported signs that indicate the 
occurrence of anxiety, based on the Hamilton scale, such as fear and worry. Also, they stated that the COVID19 pandemic period has negatively affected daily activities, referring to mood swings, negative thoughts, and discouragement. Depending on these data, there was an increase in the consumption of processed foods, sweets, and fast foods, which are more accessible and palatable, leading to a feeling of pleasure at specific times. Therefore, anxious behaviors are triggered in restrictive periods, such as quarantine, causing sporadic compulsive eating events in search of momentary satisfaction.

\section{Declaration of Potential Conflict of Interest}

The authors declare no conflict of interest.

\section{Funding}

Not applicable

\section{Data sharing statement}

No additional data are available

\section{REFERENCES}

1. Termorshuizen JD, Watson HJ, Thornton LM, Borg S, Flatt RE, MacDermod CM, Harper LE, van Furth EF, Peat CM, Bulik CM. Early Impact of COVID-19 on Individuals with Eating Disorders: A survey of $\sim 1000$ Individuals in the United States and the Netherlands. medRxiv [Preprint]. 2020 May 29:2020.05.28.20116301. doi: 10.1101/2020.05.28.20116301. Update in: Int J Eat Disord. 2020 Jul 28;: PMID: 32511555; PMCID: PMC7274236.

2. Gordilho A. Ansiedade e compulsão alimentar. [S. 1.], 4 mai. 2020. Disponível em: https://www.holiste.com.br/ansiedade-e-compulsao-alimentar/. Acesso em: 24 mai. 2020.

3. Ammar A, Brach M, Trabelsi K, Chtourou H, Boukhris O, Masmoudi L, Bouaziz B, Bentlage E, How D, Ahmed M, Müller P, Müller N, Aloui A, Hammouda O, Paineiras-Domingos LL, Braakman-Jansen A, Wrede C, Bastoni S, Pernambuco CS, Mataruna L, Taheri M, Irandoust K, Khacharem A, Bragazzi NL, Chamari K, Glenn JM, Bott NT, Gargouri F, Chaari L, Batatia H, Ali GM, Abdelkarim O, Jarraya M, Abed KE, Souissi N, Van Gemert-Pijnen L, Riemann BL, Riemann L, Moalla W, Gómez-Raja J, Epstein M, Sanderman R, Schulz SV, Jerg A, Al-Horani R, Mansi T, Jmail M, Barbosa F, FerreiraSantos F, Šimunič B, Pišot R, Gaggioli A, Bailey SJ, Steinacker JM, Driss T, Hoekelmann A. Effects of COVID-19 Home Confinement on Eating Behaviour and Physical Activity: Results of the ECLBCOVID19 International Online Survey. Nutrients. 2020 May 28;12(6):1583. doi: 10.3390/nu12061583. PMID: 32481594; PMCID: PMC7352706.

4. Zandifar A, Badrfam R. (2020). Iranian mental health during the COVID-19 epidemic. Asian Journal of Psychiatry, 51 , 101990. Disponível em: http://dx.doi.org/10.1016/j.ajp.2020.101990. Acesso em: 21 mai. 2020.

5. Goyal K, Chauhan P, Chhikara K, Gupta P, Singh MP. Fear of COVID 2019: first suicidal case in India. Asian Journal of Psychiatry, 49(101989). 2020, Disponível em: http://dx.doi.org/10.1016/j.ajp.2020.101989. Acesso em: 25 mai. 2020.

6. Barros-Delben P, Cruz RM, Trevisan KRR, Gai MJP, Carvalho RVC, Carlotto RAC, Malloy-Diniz LF (2020). Saúde mental em situação de emergência: COVID-19 [Aheadofprint]. Revista Debates in Psychiatry, 10 , 2-12. Disponível em: https://d494f813-3c95-463a898ca1519530871.filesusr.com/ugd/c37608_e2757d5503104506b30e50caa6fa6aa7.pdf. Acesso em: 25 mai. 2020.

7. Schmidt B. et al . Saúde mental e intervenções psicológicas diante da pandemia do novo coronavírus (COVID-19). Estud. psicol. (Campinas), Campinas, v. 37, e200063, 2020. Disponível em: http://www.scielo.br/scielo.php?script=sci_arttext\&pid=S0103166X2020000100501\&lng=pt\&nrm=iso. Acesso em: 21 mai. 2020.

8. Brooks SK, Webster RK, Smith LE, Woodland L, Wessely S, Greenberg N, Rubin GJ. (2020). The psychological impact of quarantine and how to reduce it: rapid review of the evidence. The Lancet, 
395 (10227), 912-920. Disponível em: http://dx.doi.org/10.1016/S0140-6736(20)30460-8. Acesso em: 25 mai. 2020.

9. Shojaei SF, Masoumi R. (2020). The importance of mental health training for psychologists in COVID19 outbreak. Middle East Journal of Rehabilitation and Health Studies, 7 (2), e102846. Disponível em: http://dx.doi.org/10.5812/mejrh.102846. Acesso em: 25 mai. 2020.

10. Wang C, Pan R, Wan X, Tan Y, Xu L, Ho CS, Ho RC. (2020). Immediate psychological responses and associated factors during the initial stage of the 2019 coronavirus disease (COVID-19) epidemic among the general population in china. International Journal of Environmental Research and Public Health, 17 (5), 1729. Disponível em: http://dx.doi.org/10.3390/ijerph17051729. Acesso em: 25 mai. 2020.

11. A viralização dos transtornos alimentares em tempos de coronavírus. [S. 1.], 24 abr. 2020. Disponível em: https://saude.abril.com.br/blog/com-a-palavra/a-viralizacao-dos-transtornos-alimentaresem-tempos-de-coronavirus/. Acesso em: 25 mai. 2020.

12. $\mathrm{O}$ que é Compulsão Alimentar. [S. 1.], 26 fev. 2016. Disponível em: http://gatda.com.br/index.php/2016/02/26/compulsao-alimentar/. Acesso em: 21 mai. 2020.

13. Transtornos alimentares. Boletim SBNp, São Paulo, SP, v.2, n.10, p. 1-30, out. 2019. Sociedade Brasileira de Neuropsicologia. Disponível em: https://sbnpbrasil.com.br/wp-content/uploads/2019/11/24Boletim_Out-2019.pdf. Acesso em: 26 mai. 2020.

14. Touyz S, Lacey H, Hay P. Eating disorders in the time of COVID-19. J Eat Disord. 2020 Apr 20;8:19. doi: 10.1186/s40337-020-00295-3. PMID: 32337045; PMCID: PMC7170399.

15. Shah M, Sachdeva M, Johnston H. Eating disorders in the age of COVID-19. Psychiatry Res. 2020 Aug;290:113122. doi: 10.1016/j.psychres.2020.113122. Epub 2020 May 29. PMID: 32480115; PMCID: PMC7259905. 